\title{
Development of methane hydrate production method
}

\author{
- A large-scale laboratory reactor for methane hydrate production tests -
}

\author{
Jiro NAGAO
}

[Reprint from Synthesiology, Vol.5, No.2, p.89-97 (2012)]

\begin{abstract}
Natural gas hydrates off the shores of Japan are valuable resources for the country. To utilize these resources, it is necessary to establish a gas production technology and investigate suitable conditions for extraction of methane from methane hydrate reservoirs. While corescale dissociation experiments yield reproducible results on how methane hydrate dissociates under various conditions, a production test at a real gas field would provide information about the type of dissociation phenomena occurring in a geological reservoir field. The performance of natural gas production from methane hydrate reservoirs is dependent upon the size and characteristics of reservoirs, such as temperature and permeability. In other words, while a core-scale dissociation test in a laboratory can demonstrate the heat transport process, dissociation in an actual reservoir is dominated by the material flow process. Thus, I believe that it is important to couple data obtained from core-scale tests with the results of field-scale tests by using a large-scale laboratory reactor in which dissociation experiments can be conducted under similar conditions to the actual reservoir. In this paper, I report the goals of the Methane Hydrate Research and Development Program being conducted by the Ministry of Economy, Trade and Industry, Japan, and describe the research objective of a large-scale laboratory reactor for methane hydrate production tests at MHRC (Methane Hydrate Research Center) of AIST (National Institute of Advanced Industrial Science and Technology).
\end{abstract}

Keywords : Methane hydrate, the Methane Hydrate Research and Development Program, MH21 Research Consortium, gas production method and modeling, large-scale laboratory reactor

\section{Introduction}

In Japan, most of the fossil fuels used as primary energy sources are imported from overseas. As natural gas is a relatively environmentally clean energy resource compared with crude oil or coal, its demand is increasing worldwide. Methane hydrate is a crystalline material comprised of methane and water molecules under high-pressure and/or low-temperature conditions. The crystalline structure of methane hydrate is shown in Figure 1. Methane hydrate is naturally distributed in permafrost and subsea environments,

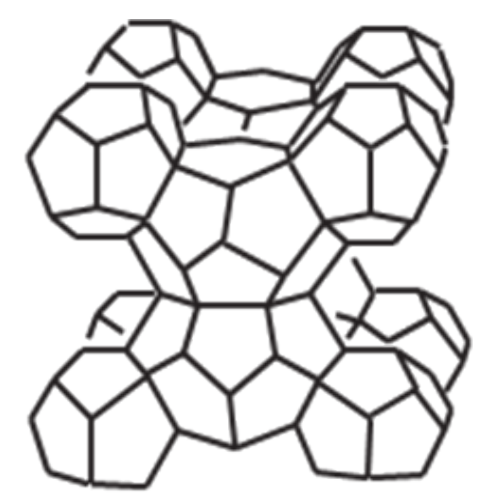

Fig. 1 Crystalline structure of methane hydrate Water molecules form "cage" structures, and methane gas molecules are captured in the water cages. which are believed to contain huge amounts of potentially extractable natural gas, of which methane is the main component (thus comes the term 'methane hydrate'). The existence of methane hydrate has been confirmed in offshore areas of Japan (Figure 2), particularly in the Nankai Trough, by means of observations made by bottom simulating reflectors (BSR). ${ }^{[1]-[3]}$ Therefore, it is believed that methane hydrate will become a valuable domestic energy resource of Japan once its production technique is established. To this end, the Ministry of Economy, Trade and Industry (METI) launched the Methane Hydrate Research and Development Program, and the Research Consortium for Methane Hydrate Resources in Japan (MH21 Research Consortium) was established. In the eastern Nankai Trough area, sedimentary core samples were obtained by the MH21 Research Consortium aboard the research vessel JOIDES Resolution. Laboratory analysis of sedimentary core samples taken from the eastern Nankai Trough area revealed that the concentration of methane hydrates is very small and methane hydrates exist within the pore spaces of sandy sediments. Kida et al. summarized the chemical characteristics of these sediment samples. ${ }^{[4]}$

Several methods have been proposed for recovering natural gas from methane hydrate reservoirs, including depressurization, thermal stimulation and inhibitor injection. ${ }^{[5]}$ The depressurization method decreases the reservoir pressure

Methane Hydrate Research Center, AIST 2-17-2-1 Tsukisamu-Higashi, Toyohira, Sapporo 062-8517, Japan E-mail: jiro. nagao@aist.go.jp

Original manuscript received September 29, 2011, Revisions received November 16, 2011, Accepted November 16, 2011 
below the equilibrium pressure of methane hydrate formation at the reservoir temperature. This method appears to be a costeffective solution for producing natural gas from methanehydrate-bearing layers. ${ }^{[6]}$ On the basis of numerical simulations of gas productivity, this method is considered to be predictable and effective for producing gas from the reservoirs consisting of alternating layers of sand and mud. However, hydrate dissociation is a very complex process of coupling heat and mass transfers with the kinetics of hydrate dissociation. Therefore, to understand the dissociation process of methane hydrate existing within the pore spaces of sandy sediments, dissociation experiments on methane-hydrate-bearing cores in a laboratory would be useful. ${ }^{[7]-[10]}$

The performance of gas production strongly depends on the size and permeability of the samples. Heat transfer is a predominant factor in dissociation experiments on methanehydrate-bearing cores performed in a laboratory (of the order of a few centimetres), whereas mass transfer dominates the dissociation process in an actual reservoir field (of the order of a few $100 \mathrm{~m}$ ). This difference in the dominant factors between core-scale experiments and field-scale production is responsible for the difference in gas production behaviours. To overcome this problem and to establish gas production conditions at a reservoir field, it is necessary to conduct

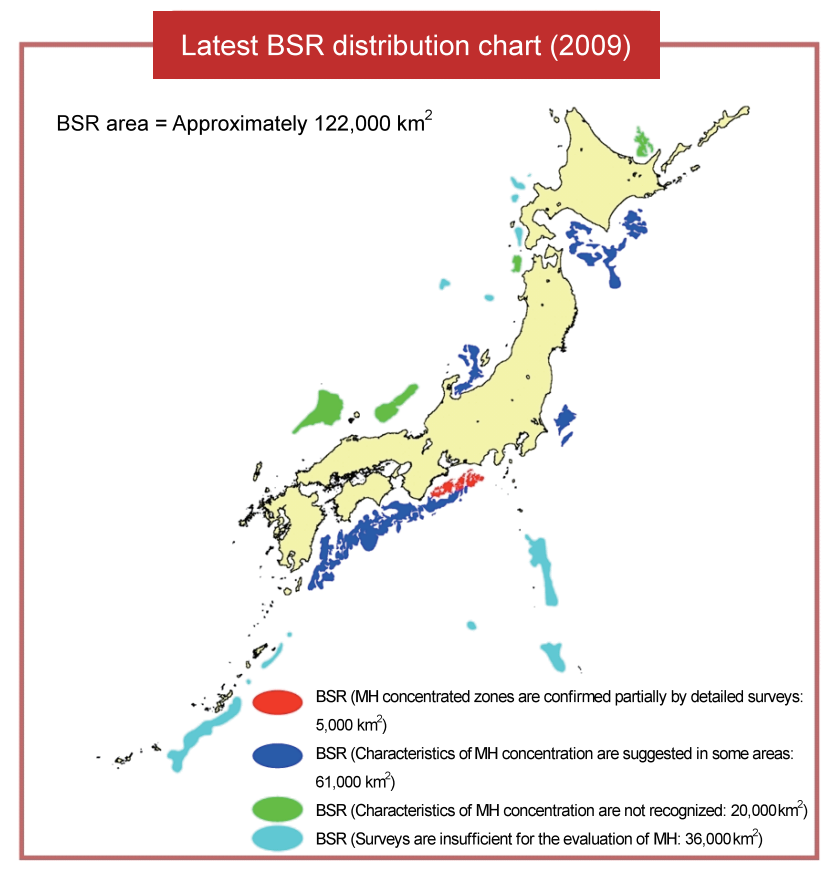

Fig. 2 Methane hydrate distribution off the shores of Japan calculated by observing bottom simulating reflectors

Red: $\mathrm{MH}$ concentrated zones are confirmed partially by detailed surveys $\left(5,000 \mathrm{~km}^{2}\right)$, Blue: Characteristics of $\mathrm{MH}$ concentration are suggested in some areas $\left(61,000 \mathrm{~km}^{2}\right)$, Green: Characteristics of $\mathrm{MH}$ concentration are not recognized $\left(20,000 \mathrm{~km}^{2}\right)$ and, light blue: Surveys are insufficient for the evaluation of $\mathrm{MH}\left(36,000 \mathrm{~km}^{2}\right)$. Total BSR area is approximately 122,000 km². (Copyright@MH21 Research Consortium) methane hydrate sedimentary core production experiments on a larger scale. Thus, AIST recently developed and introduced a large-scale apparatus for methane hydrate laboratory production tests, which can conduct gas production experiments under conditions similar to those at actual natural methane hydrate reservoir fields. In this paper, I first present an overview of the Methane Hydrate Research and Development Program. ${ }^{[1]}$ Then I describe the problems in conducting research issues such as methane hydrate production experiments at a laboratory scale, actual field production tests and numerical prediction of productivity, and finally, I report the advantage and certification of a largescale reactor developed recently to overcome such problems.

\section{Overview of Japan's Methane Hydrate Research and Development Program}

The Methane Hydrate Research and Development Program has a three-phase approach. ${ }^{[1]}$ At the starting period of this program, since AIST had high potential in gas hydrate chemistry, the Methane Hydrate Research Laboratory (now Methane Hydrate Research Center: MHRC) joined as a conducting member of research on the production method and modeling. In phase 1, from FY 2001 to 2008, the MHRC performed laboratory experiments on methane-hydratebearing cores taken from the eastern Nankai Trough, where the methane hydrate reservoir consists of alternating layers of sand and mud. The experiments showed that methane hydrate existed within the pore spaces of sand layers. Details of physical properties such as absolute permeability, porosity, methane hydrate saturation, thermal conductivity and sedimentary strength were also obtained. To evaluate gas production performances from methane hydrate reservoirs, a numerical production simulator called MH21-HYDRES was developed. Through laboratory experiments and numerical simulations using MH21-HYDRES performed by the MHRC, MH21 Research Consortium revealed that the depressurization method was determined to be the optimal production method for use in a methane-hydratebearing layer, which is the main sedimentary structure in the eastern Nankai Trough. For the first time, the validity of the depressurization method was verified by means of an onshore gas hydrate production field test conducted in March 2008 in a permafrost zone in Canada.

In phase 2, from FY 2009 to 2015, the use of methane hydrate extracted off the shores of Japan will be evaluated as a highly reliable energy resource. In addition, although it has been known that the depressurization is a useful method for gas production from methane hydrate reservoirs by laboratory characterization of core samples, the technical difficulties of commercializing gas production from methane hydrate reservoirs will be studied, where the commercialization will be inducted by public and private sectors in phase 3 from FY 2016. The MH21 Research Consortium has set up four 
research groups: the Research Group for Field Development Technology, the Research Group for Production Method and Modeling, the Research Group for Resource Assessment and the Administrative Coordination Section. The Research Group for Field Development Technology, coordinated by the Japan Oil, Gas and Metals National Corporation (JOGMEC), will implement offshore production tests, characterize the methane hydrate resource field, investigate offshore development systems, analyze the findings of a second onshore gas hydrate production test and implement longterm tests. The Research Group for Resource Assessment coordinated by JOGMEC will evaluate methane hydrate distribution off the coast of Japan and investigate methane hydrate systems. Within the Administrative Coordination Section, an R\&D team that assesses environmental impacts has been organized to analyze environmental risks and investigate appropriate countermeasures, develop technology to measure the environmental impact, assess environmental impacts in offshore production tests and make a comprehensive assessment of the environment and optimize the assessment methods used for developing methanehydrate-bearing layers.

The MHRC at AIST coordinates the Research Group for Production Method and Modeling. The aim of this group is to establish an economical and efficient gas production method by developing technologies for advanced production methods, evaluating technologies for productivity and production behaviour and evaluating technologies for sedimentary characteristics. Research activities related to each of these R\&D issues are described below.

\section{(1)Development of technologies for advanced production methods}

As mentioned above, the depressurization method can be applied to a methane-hydrate-bearing layer consisting of alternating layers of sand and mud. In such a case, the higher the initial reservoir temperature, the higher the rate of methane gas production and recovery. ${ }^{[12]}$ As gas hydrate dissociation is an endothermic reaction, the gas production rate gradually decreases as the reservoir temperature decreases. Therefore, to guarantee continuous gas production by maintaining reservoir temperature at a certain range, the development of a combined production method coupling depressurization with the other production methods is being investigated. Furthermore, to ensure long-term stable methane gas production, factors that reduce permeability of the methane-hydrate-bearing reservoir should be quantitatively analyzed, e.g. impact of sand production, ${ }^{[13]}$ skin formation and flow obstructions resulting from methane hydrate reproduction.

(2)Development of evaluation technologies for productivity and production behaviour

In order to provide reliable predictions of productivity and production behaviours for various reservoir characteristics, the MH21-HYDRES production simulator will be upgraded. To enhance the sensitivity and accuracy of gas production behaviour, analytical models and/ or routines relating to issues such as permeability of the reservoir, thermal characteristics and consolidation properties will be developed. ${ }^{[14]}$ To evaluate production damage, the calculation parameters will be justified through the verification of onshore gas hydrate production tests and offshore production tests. To evaluate production behaviours in a wide area and over a long-term period, three-dimensional reservoir models that consider discontinuity, faults and heterogeneity of the reservoirs will be developed and loaded into MH21-HYDRES. On the basis of these results, a comprehensive evaluation of the production method will be performed and an optimized economical system according to the reservoir characteristics will be developed.

\section{(3)Development of evaluation technologies for sedimentary}

\section{characteristics}

To assess environmental impacts such as the stabilization of production wells, the probability of landslides and the risk of methane gas leakages from methanehydrate-bearing sediment layers during gas production, evaluation routines called COTHMA will be developed for the sediment deformation simulator. Through a comprehensive evaluation of the mechanical properties of deep-water unconsolidated sedimentary layers by using COTHMA, the geo-mechanical stress around wells and border areas as well as long-term sediment deformation will be ascertained.

\section{Development of a large-scale laboratory reactor for methane hydrate production test}

To commercialize gas production from a methane hydrate reservoir, the technical issues described above need to be investigated. In addition, optimal production conditions that are adaptive to prevailing methane hydrate reservoir characteristics need to be ascertained. For this purpose, production tests in reservoir fields, core analyses and predictions of gas production and geo-mechanical properties obtained using MH21-HYDRES and COTHMA will yield important results, particularly when coupled with the results of investigations of the methane hydrate reservoir structure. Field production tests will yield real productivity data on real methane hydrate reservoirs, which will enhance the accuracy of numerical simulators. However, it is difficult to conduct reproducible tests under various production conditions. Numerical simulations can provide a prediction of the productivity and the stability of a methane hydrate sedimentary layer. In addition, by introducing parameters into the numerical calculations, suitable conditions of gas production for various reservoirs can be predicted. However, 
these parameters are obtained from methane-hydrate-bearing core analyses, and the obtained results will be evaluated and fine-tuned through comparisons with results from the real field production tests. A dissociation experiment on methanehydrate-bearing cores in a laboratory is useful for determining chemical and structural properties and understanding dissociation behaviour of methane hydrate distributed within pore spaces. However, because of the size of methanehydrate-bearing cores (of the order of a few centimetres), heat transfer becomes a predominant factor. As mass transfer dominates the dissociation process in an actual reservoir field, the difference in dominant factors between core-scale experiments and field-scale production would result in a difference in gas production behaviours. As mentioned above, these R\&D concepts have advantages and disadvantages and are closely related to each other, as shown in Figure 3.

To overcome the above problems, AIST developed a largescale laboratory reactor for methane hydrate production tests. Especially, to design this reactor, we have focused on solving the problem of predominant factors on hydrate dissociation, and a numerical analysis by MH21-HYDRES has been performed. ${ }^{[15]}$ From this analysis, we cleared that mass transfer dominates the dissociation process for sandy sample having over $1 \mathrm{~m}$-size. Furthermore, taking into account the research activities of the Research Group for Production Method and Modeling, the reactor was designed by considering the technical issues, as presented in Figure 4. As stated above, three main research activities need to be conducted by the
Research Group for Production Method and Modeling. Although it has been determined that the depressurization method is economically suitable for gas production from methane hydrate reservoirs off the shores of Japan, detailed conditions and procedures for depressurization remain unknown. Thus, AIST designed the large-scale laboratory reactor to aid the development of technologies for advanced production methods and to analyze the impact of sand production, skin formation, and flow obstructions. To achieve these goals, in the reactor, highly sensitive temperature and pressure sensors with a wide range and fluid flow metres are arrayed to examine a range of production conditions so that a higher gas production rate and a higher recovery rate can be obtained. To evaluate the sand production phenomenon, a sand screen is fitted to a well tube. The overall volumes of the high-pressure vessel and line tubes are estimated to reduce data error enabling comparison of the results with those of numerical predictions obtained by MH21-HYDRES. Thus, evaluation of mechanical properties can be avoided. To verify the deformation of sandy samples during gas production, it is necessary to position mechanical sensors at many locations for measuring changes in stress and confinement pressure. For this purpose, holes need to be configured in the sides and bottom of the vessel, which is a complex task.

A schematic diagram of the large-scale laboratory reactor is shown in Figure 5. The steel high-pressure vessel has an inner diameter of $1000 \mathrm{~mm}$ and a height of $1500 \mathrm{~mm}$. The vessel consists of three chambers, and its volume and weight

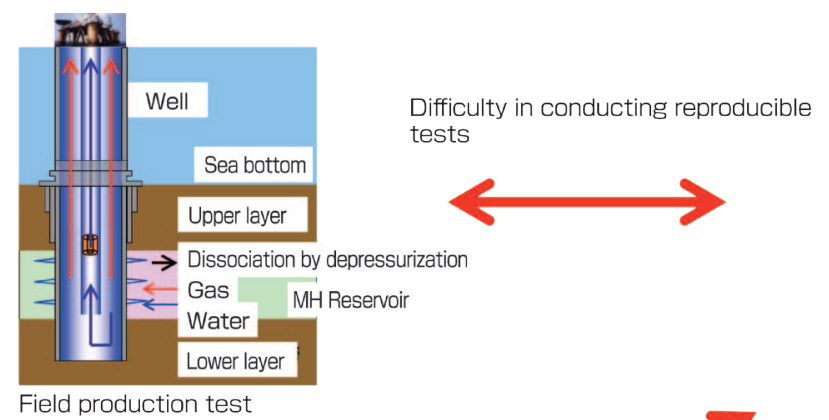

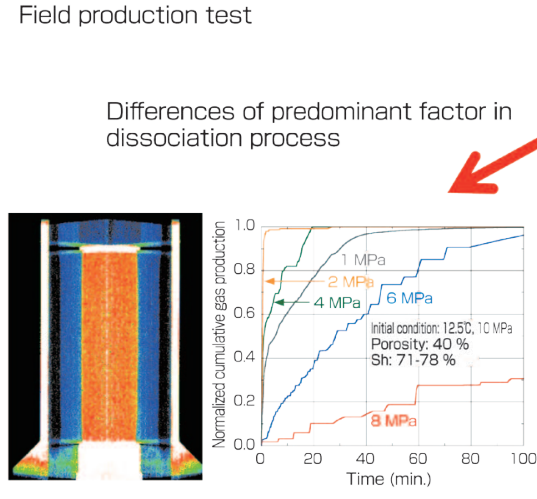

Methane-hydrate-bearing core analyses

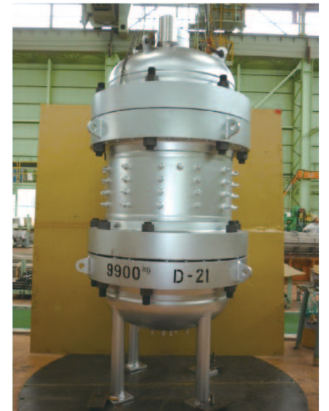

Large-scale laboratory reactor

4 Unknown accuracy of simulated results

Fig. 3 Large-scale laboratory reactor for resolving disadvantages of production tests, core analyses and production simulations These issues are the main research concepts for establishing gas production methods and evaluating conditions in methane-hydrate-bearing layers. 
are $1710 \mathrm{~L}$ and $9900 \mathrm{~kg}$, respectively. This is four times larger than the large-scale production reactor LARS developed by the SUGAR Project in Germany. ${ }^{[16]}$ The objective of the SUGAR Project is to clarify the characterization of $\mathrm{CO}_{2}$ geological storage and methane gas production using the reaction heat of $\mathrm{CO}_{2}$ hydrate generation in the methane hydrate reservoir. Our vessel can be loaded with core samples of sand with a diameter of $1000 \mathrm{~mm}$ and a length of 1000 $\mathrm{mm}$. An inner plate is placed on top of the methane hydrate sedimentary sample to exert an overburden pressure of up to $16.5 \mathrm{MPa}$; this pressure is similar to that in a subsea environment. The overburden pressure is supplied by injecting water into the space between the upper chamber and the inner plate. A production well is simulated using a steel pipe with a diameter of $100 \mathrm{~mm}$ and a length of 1000 $\mathrm{mm}$ with 32 holes drilled along its length; the pipe is placed at the centre of a sandy sample layer. A sand screen can be placed over the holes to terminate sand production. A total of 50 holes in the sides and 19 holes in the bottom of the vessel are provided to allow the insertion of gas, water and temperature and pressure sensors. The position of sensors can be adjusted depending on the characteristics of the sand sample and the production conditions. To simulate conditions of a methane hydrate reservoir at the eastern Nankai Trough area, the vessel is placed in a large cabinet that can control the temperature of the high-pressure vessel from -5 to $20^{\circ} \mathrm{C}$.

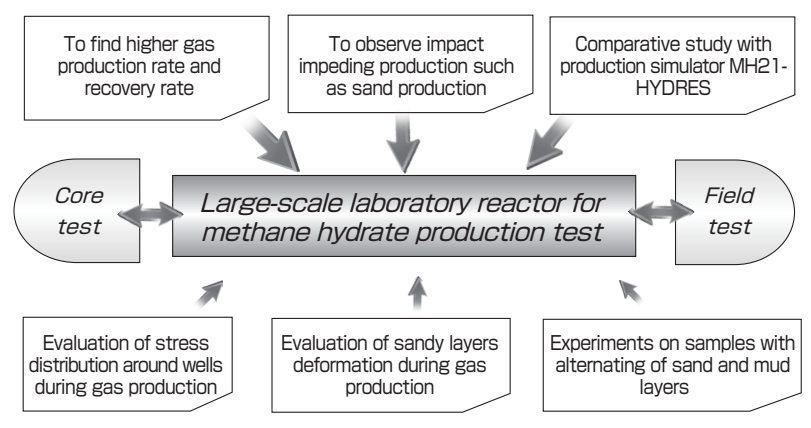

Fig.4 Relationship between the experimental issues on large-scale laboratory reactor and the roles of research teams of the Research Group for Production Method and Modeling

Evaluation of production behaviours such as (1) enhancement of production rate and recovery rate and (2) analysis of impact impeding production are the main experimental issues on a large-scale laboratory reactor. Also, various production conditions to obtain a higher gas production rate and recovery rate can be examined. The experimental results are compared with those from small scale core experiments and analyses of MH21-HYDRES, which is a numerical model of a large-scale laboratory reactor. Finally, the results will be compared to production results of real field tests which will be held in FY2012. However, research regarding geo-mechanical characterization has not been conducted. To achieve relatively uniform methane hydrate formation within the pore spaces of a sandy sample, the positions of the perforations cannot be adjusted for experiments on samples with alternating layers of sand and mud.
Holes in the sides and bottom of the vessel for the insertion of gas and water are connected to $\mathrm{CH}_{4}$ gas supplier and pumps that supply pure water into the sandy sample layers, respectively. The production well is connected to a gas and water separator. Real-time observations of the rate of the production of gas and water as well as the amount of fine sand particles can be performed under various temperature and pressure conditions.

Pure water is injected into the high-pressure vessel via the holes in the sides of the vessel and the centre pipe. Once the designated amount of pure water has been filled in the vessel, sand particles are added to the pure water, and vibration is applied to ensure homogeneous accumulation of sand particles. After the vessel is filled with wet sand particles, the inner plate is positioned above the sand sample layer, and the top chamber is closed. Pure water is injected into the interior of the top chamber to apply overburden pressure to the sandy sample layer by pressurizing the inner plate. To adjust the water content, water in the sandy sample layer can pass through the holes in the bottom of the vessel.

For the formation of methane hydrate in the sandy sample layer and control of the confinement pressure, the flow rate of $\mathrm{CH}_{4}$ is adjusted. $\mathrm{CH}_{4}$ is continuously supplied via holes in the sides of the vessel. The temperature of the cabinet is decreased below the equilibrium temperature of methane hydrate formation. By calculating the injected volume of methane gas and the initial water content, the end of the methane hydrate formation can be estimated. After methane hydrate formation, pure water is injected into the pore spaces of the sandy sample layer because natural gas hydrate reservoirs are usually saturated with water.

The top of the centre pipe is connected to a backpressure regulator. To examine the depressurization method, the pressure value of the regulator is adjusted to a designated pressure. After adjustment, gas and water flow out through the centre pipe, which may contain fine sand components. The centre pipe is connected to the gas-water separator, and each line tube is connected to a fluid flow metre that measures water and gas volumes during the experiment. To evaluate the sand production phenomenon, a water flow line is connected to the accumulation chamber to collect the fine sand particles.

Figure 6 shows the predictions of water and gas production by the MH21-HYDRES production simulator using the results of depressurization experiments conducted in the large-scale laboratory reactor. The results show the water and gas production behaviours when pressure is decreased from 10 to $3 \mathrm{MPa}$. The parameters for the numerical simulation were temperature of $10^{\circ} \mathrm{C}$, pressure of $10 \mathrm{MPa}$, permeability of sandy sample layer of $1000 \mathrm{mD},{ }^{[17]}$ initial effective permeability of $26 \mathrm{mD},{ }^{\text {Term } 1}$ hydrate saturation of $60 \%$ and 
water saturation of $40 \%$. From these results, gas production shows a peak during the first period, indicating that mass transfer is predominant in the dissociation process. Gas production experiments conducted using depressurization to ascertain the relationship between the degrees of reduction in pressure and the gas production rate have been underway. The obtained results will be compared with those obtained from a numerical simulation study conducted using the MH21-HYDRES production simulator. This study will contribute to the first field production test to be conducted off

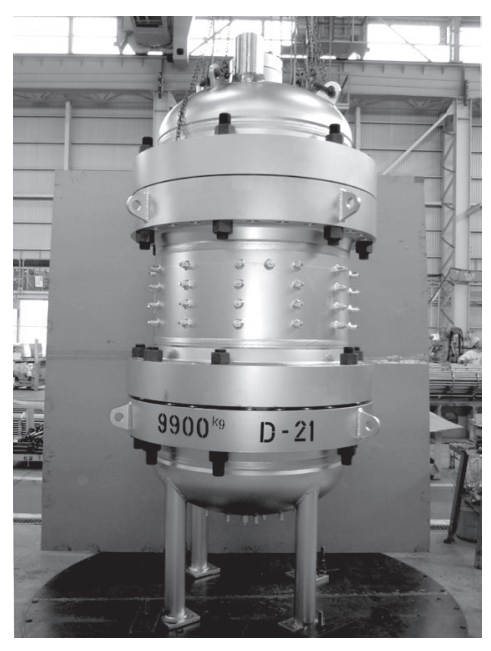

(a) High-pressure vessel of the large-scale laboratory reactor

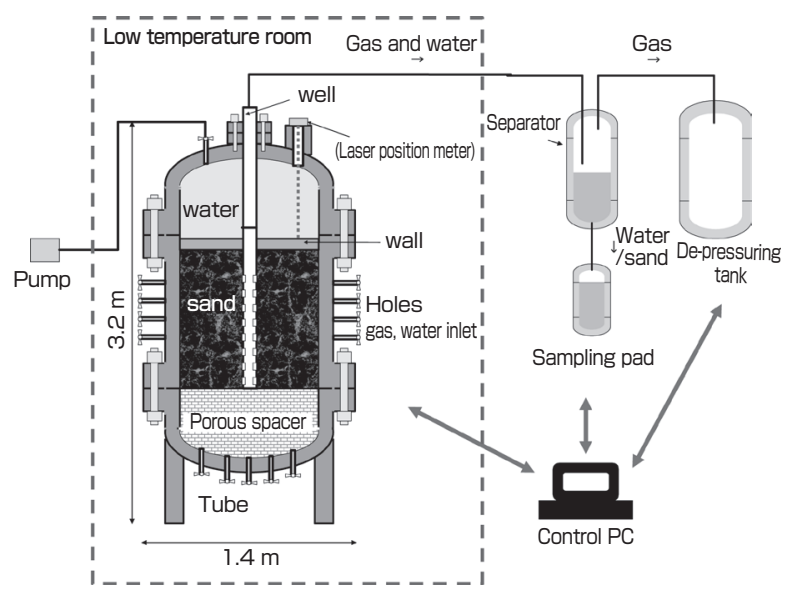

(b) Schematic flow diagram of the large-scale laboratory reactor

Fig. 5 Schematic illustrations of the large-scale laboratory reactor

To aid the development of technologies for advanced production methods and to analyze the impact of sand production, skin formation and flow obstructions, the highly sensitive temperature and pressure sensors with a wide range and fluid flow metres are arrayed to side holes of the vessel. To evaluate the sand production phenomena, a sand screen is fitted to a well tube. Water and fine sand are collected in a sampling pod arrayed to the water/gas separator. The overall gas volume is measured at de-pressuring tank arrayed to the water/gas separator. All measured data were collected in a PC automatically. the shore of Japan in FY 2012.

\section{Acknowledgements}

This study was financially supported by the Research Consortium for Methane Hydrate Resources in Japan (MH21 Research Consortium) to carry out the Methane Hydrate R\&D Program conducted by METI. I thank Dr. Hideo Narita, Dr. Yoshihiro Konno, and Dr. Hiroyuki Oyama of AIST for their valuable suggestions in the preparation of this manuscript.

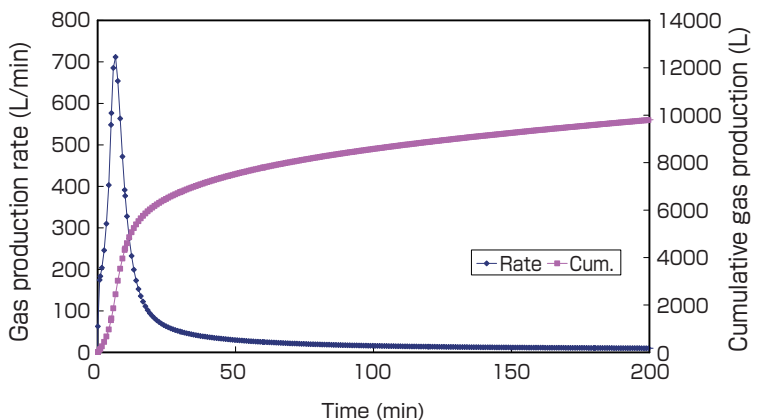

(a) Gas production behaviour

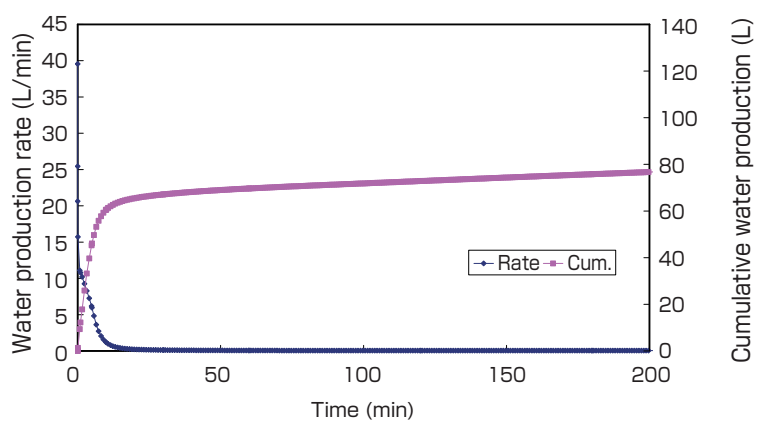

(b) Water production behaviour

Fig. 6 Predictions of gas and water productions based on depressurization experiments in the large-scale laboratory reactor using the MH21-HYDRES production simulator

A peak during the first period in gas production behaviour indicates that mass transfer is predominant in the dissociation process. 


\section{Terminology}

Term 1. Darcy (D): a traditional unit for permeability. The SI unit for pearmeability is $\mathrm{m}^{2}$. 1D is ca. $10^{-12} \mathrm{~m}^{2}$.

\section{References}

[1] M. Satho: Distribution and resources of marine natural gas hydrates around Japan, Proc. 4th Int. Conf. Gas Hydrate, 175 (2002).

[2] F. Colwell, R. Matsumoto and D. Reed: A review of the gas hydrates, geology, and biology of the Nankai Trough, Chemical Geology, 205, 391 (2004).

[3] Bottom simulating reflector (BSR) is observed in seismic profile data, which broadly mimics the relief of the sea floor. This boundary is to mark the pressure and temperature dependent base of the methane-hydrate stability field. Namely, above the BSR, methane hydrate exists as hydrate.

[4] M. Kida, K. Suzuki, T. Kawamura, H. Oyama, J. Nagao, T. Ebinuma, H. Narita, H. Suzuki, H. Sakagami and N. Takahashi: Characteristics of natural gas hydrates occurring in pore spaces of marine sediments collected from the eastern Nankai Trough, off Japan, Energy \& Fuels, 23, 5580 (2009).

[5] E. D. Sloan: Clathrate Hydrates of Natural Gases, 2nd ed., Marcel Dekker (1998).

[6] M. Kurihara, A. Sato, H. Ouchi, H. Narita, Y. Masuda, T. Saeki and T. Fujii: Prediction of gas productivity from Eastern Nankai Trough methane-hydrate reservoirs, Offshore Technology Conference, SPE international, Society of Petroleum Engineers, OTC-19382 (2008).

[7] M. H. Yousif, P. M. Li, M. S. Selim and E. D. Sloan: Depressurization of natural gas hydrates in Berea sandstone cores, Journal of Inclusion Phenomena and Molecular Recognition in Chemistry, 8, 71 (1990).

[8] Y. Kamata, T. Ebinuma, R. Omura, H. Minagawa and H. Narita: Decomposition behaviour of artificial methane hydrate sediment by depressurization method, Proc. 5th Int. Conf. Gas Hydrate, 3016 (2005).

[9] T. J. Kneafsey, L. Tomutsa, G. J. Moridis, Y. Seol, B. M. Freifeld, C. E. Taylor and A. Gupta: Methane hydrate formation and dissociation in a partially saturated core-scale sand sample, Journal of Petroleum Science \& Engineering, $56,108(2007)$.

[10] H. Oyama, Y. Konno, Y. Masuda and H. Narita: Dependence of depressurization-induced dissociation of methane hydrate bearing laboratory cores on heat transfer, Energy \& Fuels, 23, 4995 (2009).

[11] Detail and research planning of the Japan's Methane Hydrate Research and Development Program and research scheme of Research Consortium for Methane Hydrate Resources in Japan (MH21 Research Consortium) are described at http:// www.mh21japan.gr.jp/english/.

[12] Y. Konno, Y. Masuda, Y. Hariguchi, M. Kurihara and H. Ouchi: Key Factors for Depressurization-Induced Gas Production from Oceanic Methane Hydrates, Energy \& Fuels, 24, 1736 (2010).

[13] H. Oyama, J. Nagao, K. Suzuki and H. Narita: Experimental Analysis of Sand Production from Methane Hydrate Bearing Sediments Applying Depressurization Method, J. MMIJ, 126, 497-502 (2010) (in Japanese).

[14] Y. Konno, H. Oyama, J. Nagao, Y. Masuda and M. Kurihara: Numerical Analysis of the Dissociation Experiment of Naturally Occurring Gas Hydrate in Sediment Cores
Obtained at the Eastern Nankai Trough, Japan, Energy \& Fuels, 24, 6353 (2010).

[15] Y. Konno, Y. Masuda, H. Oyama, M. Kurihara and H. Ouchi: Numerical Analysis on the Rate-Determining Factors of Depressurization-Induced Gas Production from Methane Hydrate Cores, Proc. Offshore Technology Conference 2010, 20591 (2010).

[16] J. Schicks, E. Spangenberg, R. Giese, B. Steinhauer, J. Klump and M. Luzi: New Approaches for the Production of Hydrocarbons from Hydrate Bearing Sediments, Energies, 4, 151 (2011).

\section{Author}

\section{Jiro NAGAO}

Completed the two-years masters course at the Graduate School of Engineering, Hokkaido University in 1991. Joined the Government Industrial Research Institute, Hokkaido, Agency of Industrial Science and Technology, Ministry of International Trade and Industry in 1991 (current AIST). Received Doctor (Engineering) in 2000 from Hokkaido University. Became

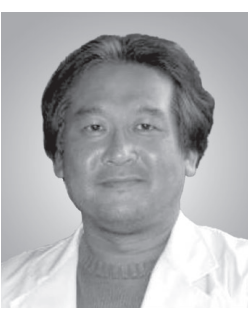
the leader of the Production Technology Team, Methane Hydrate Research Center in 2009. Also became the leader of the Research Group for Production Method and Modeling of the MH21 Research Consortium in 2010. Engaged in research of physics and chemistry of clathrate materials and development of production method and modelling of gas hydrate resources.

\section{Discussions with Reviewers}

\section{General construction of the manuscript Comment (Hiroshi Tateishi, AIST)}

For the development of the gas production technology from methane gas hydrate reservoirs, this manuscript first explains the overview of Japan's Methane Hydrate Research and Development Program, and then the development of the apparatus for methane hydrate production tests carried out by the author is described. The construction of the manuscript is rather unusual, because the experimental results from the apparatus have not yet been obtained at present. In spite of this fact, the manuscript is acceptable after revision because publication of such type of manuscript is requested from the outside. From the standpoint of the journal, Synthesiology, the manuscript lacks issues as pointed out in the following comments. From the viewpoint of "synthesis," there is a dual structure of synthesis: one is micro-level technology synthesis to integrate elemental technologies toward the development of the apparatus which is the main purpose of the present manuscript, and the other is macro-level system synthesis to integrate the results obtained with the apparatus toward the development of the production system. For the revision of the manuscript, please take these points into consideration. Answer (Jiro Nagao)

Concerning the development of a large-scale laboratory apparatus for the optimization of production conditions toward commercial utilization of methane hydrate, the outline of the program, the R\&D issues of the Research Group for Production Method and Modeling of MH21 Consortium coordinated by the MHRC at AIST, and the important issues to be analyzed with this apparatus have been described. In response to the reviewer's 
comments, the author has added and revised the description in the text and the reference. However, the development of the production system depends not only on the production method, but also on the economic evaluation of methane production including the combination of machines in production tests at the sea bed conducted by JOGMEC. Thus, it is difficult to consider the validity of the production system based only on the tests with the large-scale apparatus. Therefore, the author has not described the development of the production system in this paper.

\section{The role of MHRC}

\section{Comment (Hiroshi Tateishi)}

In the latter half of "2. Overview" section, the goals of $R \& D$ issues in phase 2 at MHRC are explained. However, the description is sudden and difficult to understand for the readers since the relevance of phase 2 with phase 1 is not explained. Brief explanation for the following points is required: why MHRC is assigned for this part of $R \& D$, what kind of results MHRC obtained in phase 1 , and how the results obtained in phase 1 are connected to phase 2 .

Answer (Jiro Nagao)

The author has added the following explanation. At the start of the program, the Methane Hydrate Research Laboratory of AIST (the present Methane Hydrate Research Center) participated in the MH21 Consortium as the research supervisor of R\&D of production method \& modeling in phase 1 since the laboratory had high level knowledge on methane hydrate engineering. The foregoing explanation has been connected to the subsequent description of implementation challenges and the research results. It has been found that depressurization is effective for the gas production method from the methane hydrate resource as a research result in phase 1 . The finding is linked to the research purpose of phase 2 (technology advancement toward commercialization).

\section{Development of $1 \mathrm{~m}$-size test apparatus Comment (Hioshi Tateishi )}

1. I can understand the logic that thermal decomposition is dominant in $\mathrm{cm}$-size samples whereas mass transfer is dominant in the actual $100 \mathrm{~m}$-size bed, therefore a test filling the gap in between is required. Yet it is difficult to judge the adequateness of the specifications of the apparatus since no quantitative explanation is given on the scale boundary that separates the dominant factors. It seems difficult to set a strict boundary, but explanation is required such as, "Since critical scale is around this level because of such and such reasons, a 1m-size apparatus is adequate enough."

2. Since the explanation of the specifications of the apparatus is simply listed, it is not clear where the focus is. For example, if the author arranges the explanation in the order of main items to test with the apparatus, technological issues and required functions to achieve the issues, the ways to clear the issues, the readers can understand the idea more easily. Especially, the manuscript lacks the explanation of originality of the MHRC.

3. The author briefly explains the large-scale production apparatus LARS developed by the SUGAR Project in Germany. Since only the size is mentioned, it is difficult to understand the significance of the comparison. Please describe the purpose and design concept of the LARS and explain the difference of the two apparatuses, LARS and the apparatus of MHRC.

Answer (Jiro Nagao)

1. In order to design our apparatus, we have focused on solving the problem of predominant factors of hydrate dissociation. The sample size dependence of the rate-determining step has been investigated by using the production simulator, MH21-HYDRES. Another study shows that in the case of permeability of $10 \mathrm{mD}$ order, the mass and heat transfers become comparable at the sample size of $0.5 \mathrm{~m}$ (Konno et al. Proc. Offshore Technology Conference 2010, 20591 (2010)). On the basis of the study and the analysis, we have judged that mass transfer dominates the dissociation process with an apparatus of over $1 \mathrm{~m}$-size. We have added the explanation in lines 3-8 on page 93 and reference No.15.

2. On designing the apparatus, we have set the most important $R \& D$ issues to be investigating the dependence of productivity of the depressurization method on the permeability of the sample and finding the most suitable depressurization conditions, and analyzing quantitatively the impact of sand production, skin formation, and flow obstructions. The explanation of the functions prepared to clear the issues, their technological issues and the ways to clear the issues have been added to the manuscript.

3. It was described in a paper that the objective of the SUGAR Project is to clarify the characteristics of $\mathrm{CO}_{2}$ geological storage and that the apparatus was introduced to carry out the methane hydrate decomposition using the reaction heat generated in the formation of $\mathrm{CO}_{2}$ hydrate. The explanation of the objective has been added to this manuscript. However, the author has not obtained the accurate information on the design concept of the apparatus and cannot explain it. 